\title{
Hydrodynamic Effects of Gales on Lake Erie
}

\author{
Garbis H. Keulegan
}

\begin{abstract}
The coefficients of wind stress and the sea roughness are derived from records of water levels and wind intensities relating to gales passing over Lake Erie during the past fifty years. The reduction of wind velocities measured at various elevations in four cities on the lake shore to a single "effective wind velocity" over the lake is explained. A theoretical determination of the wind tides agrees well with the observations. The coefficient of wind stress derived from the observations is nearly the same as that obtained by Neumann from observations in the Gulf of Bothnia. Both the coefficient of wind stress and the sea roughness are found to decrease with increasing wind velocities.
\end{abstract}

\section{Introduction}

For a wind blowing steadily with a uniform intensity over a lake, the relationship between the wind intensity and the frictional stress induced at the water surface may be found by considering the wind tides produced at the ends of the lake. Wind tides are those displacements of the water level from the initial undisturbed level that are due solely to the action of the wind. The relationship involves a characteristic quantity called the coefficient of wind stress. There will be an element of uncertainty in the coefficient derived if the wind stress corresponding to a wind of constant intensity is a function of distance, or fetch, and only the wind tides at the lake ends are known. In such cases the analysis yields average values of the wind stresses, and if it be true that the stress is also a function of fetch, the derived coefficient of wind stress will be different for lakes of different lengths.

Another source of uncertainty in the values of the coefficient of wind stress is in the derivation of the formula which relates the wind stress to the wind tides. In working out the formula, due attention must be given to the nonuniformity of depth of water in the lake and of width of the lake surface, and also to the magnitude of the friction at the bottom of the lake. The turbulence pattern in the waters of a lake under the action of wind is at the present time far from being depicted. The partition of velocities in the drift current at the upper layers and in the returning gravity current in the lower layers, and the magnitudes of the mixing lengths, are questions which have not been studied. Lack of information of this nature prevents one from appraising accurately the the frictional force at the lake bottom. Besides, if the boundary of a lake exhibits very marked irregularities and there are also numerous islands distributed in the regions close to the lake ends, the derivation of the exact wind tide formula is very difficult and in some cases may be impossible. These difficulties are present to some extent in the case of Lake Erie.

A second problem in connection with the action of wind on lakes is the relationship between the effective roughness of the sea and the velocity of the wind. Meteorologists regard the Prandtl law of velocities as representing satisfactorily the state of movement of the wind in the layers of air above the water surface. This law requires a roughness length which is called the roughness of the sea. Once the coefficient of wind stress based on the wind velocities at points of known distance from the surface of the water is known for a given lake, the sea roughness is readily obtained from the value of the coefficient. Since sea roughness is an inferred quantity and is a function of stress, the likelihood exists that the sea roughness is a function of fetch. If the determination of roughness is made on the basis of average stresses at the lake surface, the value of roughness may vary for a given wind velocity for lakes of different lengths.

It is proposed in the present work to obtain the values of the coefficient of wind stress and of the sea roughness for Lake Erie. The determinations are brought about by considering the maximum wind tides observed during the severe westerly gales passing over Lake Erie in the past half century.

\section{Sources of Original Data}

The hydrographic charts of the United States Lake Survey showing the surface changes of Lake Erie during gales constitute the chief source of material for the present investigation. These charts show the water stages at the extremities of the lake, and the values of the hourly movement of wind and its direction for a few stations on the southern coast. Two examples of such charts are given by Freeman [1].

The stations for which charts of water stages are given have been changed from time to time. Buffalo and Amherstburg, or Gibraltar, are the localities near the ends of the lake for which the water stages are given for westerlies during the earlier years. For easterlies the corresponding localities are Toledo and Buffalo. In these charts complete wind data are shown for Toledo, Cleveland, Erie, and Buffalo. In the charts of later years, water stages are shown for Toledo and Buffalo. However, the representation of wind data has not always been complete, and in such instances the missing information has been received from the U. S. Weather Bureau.

It was desired to handle the analysis on the basis of the wind tides observed at Toledo and Buffalo. The data for Toledo, where missing, were deduced from the data for Gibraltar and Amherstburg. This is feasible as in general a correlation exists for the wind tides of nearby localities. The desired correla- 
tion factor could be determined, for in some of the charts the simultaneous values of the water stages at Toledo and Amherstburg are given. In this determination use was made also of Blunt's work [2].

In the determinations of the coefficients of wind stress, the observed wind tides must be corrected for barometric pressure changes. Data needed are the hourly values of the barometric pressures at Toledo and Buffalo for the periods of the gales considered. For these the U. S. Weather Bureau has kindly allowed us access to the proper records.

\section{Determination of Effective Winds}

\subsection{City Wind Velocities at a Common Elevation}

The evaluation of the coefficient of wind stress will be made with respect to wind velocities at a height of $25 \mathrm{ft}$ above the water surface of the lake. As these velocities were not observed and the only available velocities are those measured over the cities of Toledo, Cleveland, Erie, and Buffalo, the lake wind velocities will be deduced from the city velocities. The reduction to the desired values will be made in three steps.

As the anemometer heights during a given period have been different in the cities mentioned, or have been changed in a given city from time to time, the first step of the analysis is to reduce all the measured wind velocities to the values appropriate to a common elevation. The elevation selected was $165 \mathrm{ft}$ above the ground.

The region of air above the ground may be conceived to consist of two layers, the boundary layer below and the layer of frictional influence above. The boundary layer is relatively thin, and the movement of air in it is controlled entirely by frictional stress as horizontal pressure gradient and deflecting forces may be neglected. In a vertical traverse the frictional stress is constant, and the direction of the stress vector coincides with the direction of the wind. For this layer, Prandtl [3] gives the law of velocities

$$
\frac{u}{u_{*}}=5.75 \log \frac{z}{\epsilon}
$$

where $z$ is the elevation of a point at which the velocity is $u, u_{*}$ is the shear velocity, and $\epsilon$ is the effective roughness. Denoting the frictional stress at the ground by $\tau_{0}$ and the density of air by $\rho_{a}$,

$$
u_{*}=\sqrt{\tau_{0} / \rho_{a}} .
$$

When the actual roughness is large, the reference level from which to measure the height $z$ is a matter of importance. It may be that in cities with an a verage height of buildings of $2 K$ the reference level can be taken at the distance $K$ from the ground. Then, following Prandtl, the effective roughness $\epsilon_{2}$ of a city may be taken as

$$
\epsilon_{2}=2 K / 30 \text {. }
$$

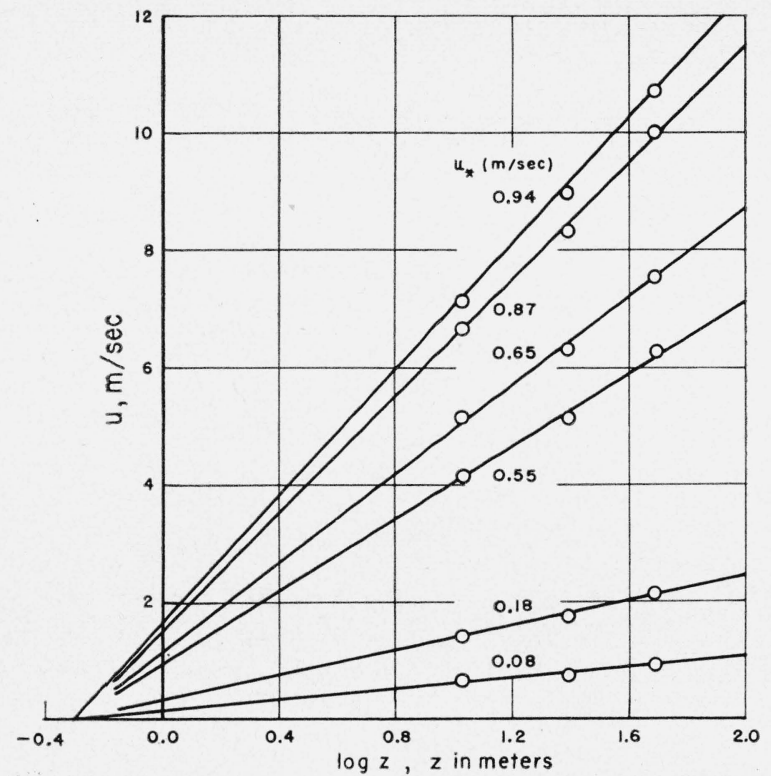

FIGURE 1. Relation of wind velocity, $u$, to height over the city of Tokyo, z, from measurements by Siotani and Yamamoto.

We may now consider, to test the utility of the rules given above, a known case of measured velocities over a large city. In the autumn of 1946 Siotani and Yamamoto [4] obtained the air velocities over the central part of Tokyo at elevations of 60 , $55,45,35$, and $25 \mathrm{~m}$ above the ground, using hotwire anemometers on the tower at the Central Meteorological Observatory. The neighboring buildings being 10 to $20 \mathrm{~m}$ in height, $K$ in this case was $7.5 \mathrm{~m}$.

In figure 1 are reproduced some of the velocity values from the original curves of these authors. In the plot $z$ is the height in meters measured from the reference level of $7.5 \mathrm{~m}$ above the ground. The straight lines drawn through the points meet at a common point on the abscissa axis, log $\epsilon_{2}=-0.3$. Thus the effective city roughness is $\epsilon_{2}=0.5 \mathrm{~m}$, a result satisfying the rule implied by eq 3 . Denoting by $u_{0}$, the value of the velocities to be read from the straight lines of the figure for $z=1$, the shear velocity may be computed as $u_{*}=-\left(u_{0}\right) /(5.75 \mathrm{log}$ $\left.\epsilon_{2}\right)$. The shear velocities thus computed are also entered in figure 1. Representing the data in figure 1 in dimensionless form, the results are the three points in figure 2. The distribution of the points confirms the relation given by eq 1 , and this fact points to the possibility of applying the rule to cities in general.

Estimating the average height of buildings in American cities as $30 \mathrm{ft}$, the effective roughness may be taken to be $1 \mathrm{ft}$. Measuring the elevation of points $z$ from a reference level $15 \mathrm{ft}$ above the ground, denoting the position of an anemometer by $z_{a}$, the measured velocity by $u_{a}$, the standard height by $z_{2}(=150 \mathrm{ft})$, the velocity at this height by $u_{22}$, the roughness of the city by $\epsilon_{2}(=1 \mathrm{ft})$, the formula to reduce the anemometer velocities to the 


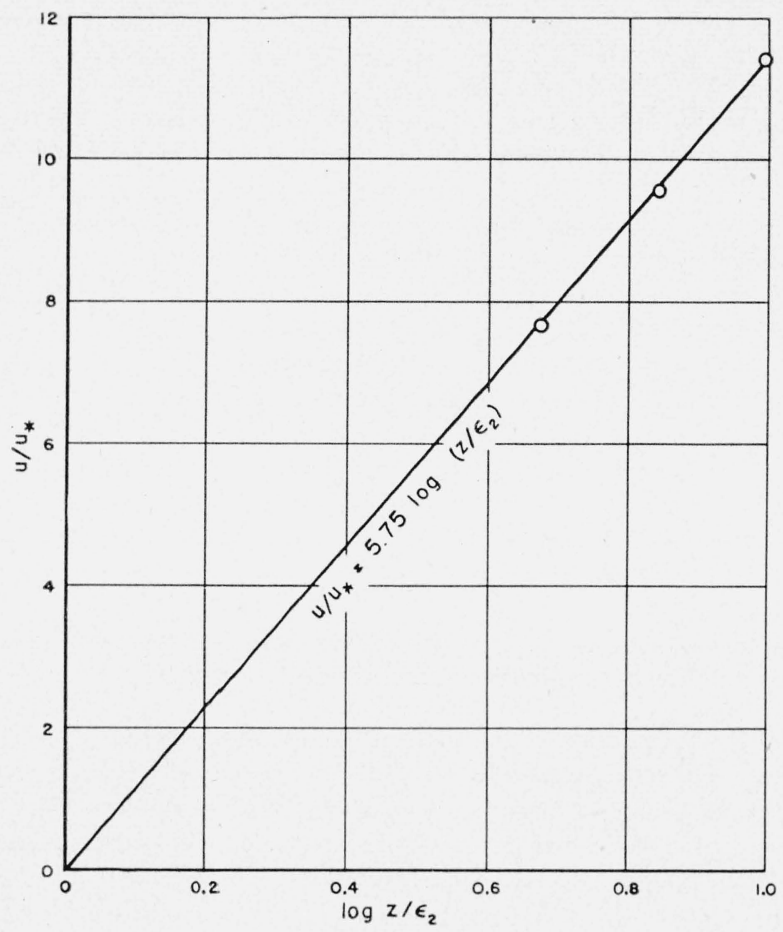

FIGURE 2. Relation of wind velocities measured over the city of Tokyo to the Prandtl law.

velocities at standard heights is

$$
\frac{u_{22}}{u_{a}}=\log \frac{z_{2}}{\epsilon_{2}} / \log \frac{z_{a}}{\epsilon_{2}} .
$$

The curve in figure 3 is established through this relation and is used to reduce the anemometer velocities to the velocities corresponding to the standard height $z_{2}(=150 \mathrm{ft})$. For the purpose of comparison a second curve is shown, evaluated with $\epsilon_{2}=2 \mathrm{ft}$. The disparity between the curves being small, it is seen that errors arising from the uncertainties in the exact value of the city roughness are not very appreciable.

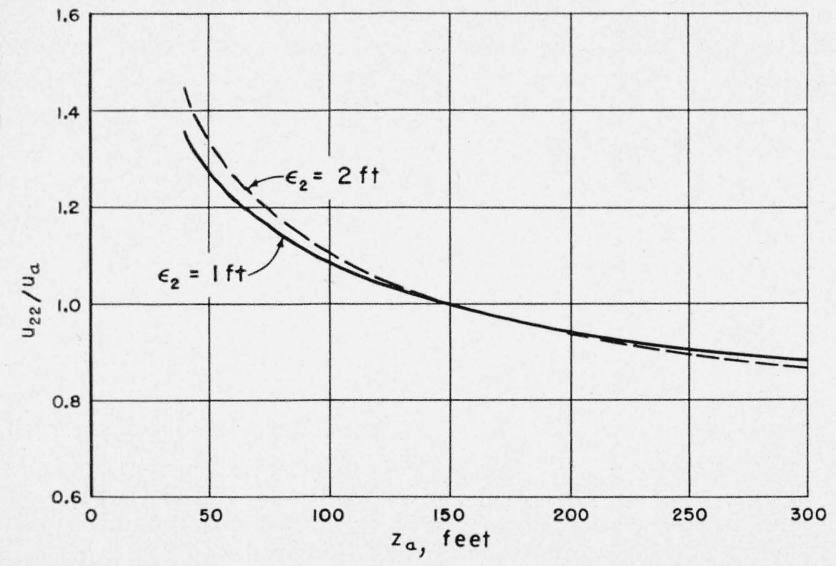

FiguRE 3. Ratio of wind velocity at a standard height of 150 feet above a city, $u_{22}$, to the wind velocity indicated by an anemometer, $u_{a}$, as a function of the height of the anemometer, $z_{a}$, and the roughness of the city, $\epsilon_{2}$.

\subsection{Wind Velocities Over the Lake Surface}

The second step is to infer the wind velocities over the lake surface from the wind velocities $u_{22}$ corresponding to the standard height $z_{2}(=150 \mathrm{ft})$ over the city. To establish the desired values resort is to be made to the characteristic relationships involving the various quantities of the layer of frictional influence. Regarding the hydrodynamics of the layer, the analysis of Rossby [5] proves to be particularly fruitful.

The quantities that will be of value here are the height, $H$, of the boundary layer, the wind velocity, $U_{H}$, at the upper surface of the boundary laver, the gradient wind, $U_{g}$, and the angle $\phi_{s}$ between the direction of the gradient wind and the direction of the wind in the boundary layer. The Rossby relations are

$$
\begin{aligned}
& U_{H}=U_{g}\left(\cos \phi_{s}-\frac{1}{\sqrt{2}} \sin \phi_{s}\right), \\
& H=0.54 k^{2} \frac{U_{g}}{f} \sin \phi_{s}, k=0.065,
\end{aligned}
$$

and

$$
\log U_{g} / f_{\epsilon}=1.694 \cot \phi_{s}-\log \sin \phi_{s}+1.441 .
$$

Here $f$ represents the quantity $f=2 \Omega \sin \lambda, \Omega$ being the angular speed of the earth's rotation, and $\lambda$, the latitude. The roughness of the surface below is $\epsilon$. The importance of the effective roughness, of the ground or of the sea, for the quantities pertaining to the lower layers of the atmosphere can easily be seen.

Once it is assumed that the magnitude and the direction of the gradient wind are the same over the lake water and over the coastal regions next to the lake, eq 5, 6, and 7 provide the means by which a relationship may be established connecting the velocity of the wind over the surface of the lake with the velocity of the wind over a city on the borders of the lake.

For a second definition of terms the diagram in figure 4 may be consulted. Assuming a gradient

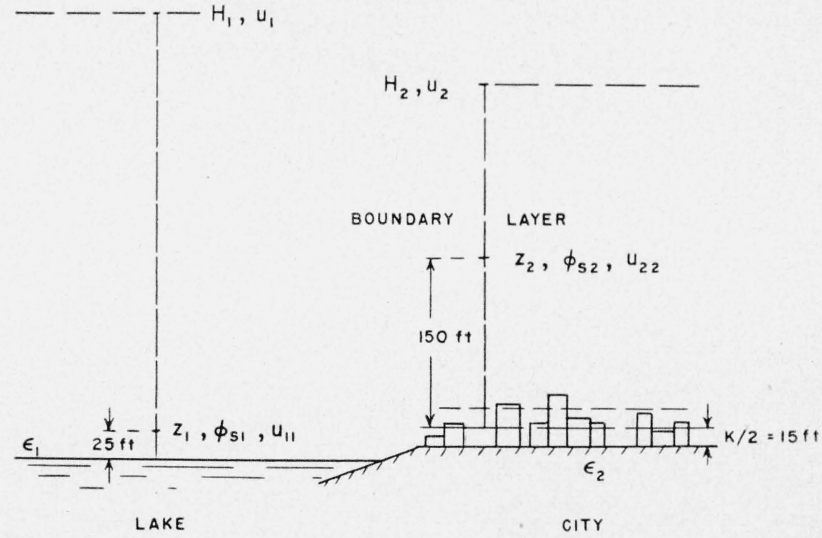

Figure 4. Notation diagram for winds over a lake and a city on its shore. 
wind constant both in intensity and in direction blowing in the higher regions over the lake and over the city, let $H_{1}$ denote the height of the boundary layer over the lake and $H_{2}$ that over the city. Let $\epsilon_{1}$ denote the effective sea roughness and $\epsilon_{2}$ the roughness of the city. Let $u_{1}$ denote the wind velocity at the upper surface of the boundary layer over the lake and $u_{2}$ that over the city. Let $u_{22}$ denote the wind velocity over the city at the standard height $z_{2}(=150 \mathrm{ft})$ and $u_{11}$ that over the lake at the standard height $z_{1}(=25 \mathrm{ft})$. Let $\phi_{s 2}$ be the angle between the direction of the wind over the city, and the direction of the gradient wind, and $\phi_{s 1}$ the corresponding angle over the lake. Then, according to the Prandtl law of velocities given by eq 1 , the formula which reduces the wind velocities over the city to those over the lake is

$$
\frac{u_{11}}{u_{22}}=\frac{u_{1}}{u_{2}}\left[\frac{\log \frac{z_{1}}{\epsilon_{1}}}{\log \frac{H_{1}}{\epsilon_{1}}} / \frac{\log \frac{z_{2}}{\epsilon_{2}}}{\log \frac{H_{2}}{\epsilon_{2}}}\right],
$$

the computations being made through eq 5, 6, and 7. The results are shown in the form of curves in figure 5 , with the ratio $u_{11} / u_{22}$ plotted as function of $u_{22}$ for various sea roughnesses. It is seen that the ratio $u_{11} / u_{22}$ for a given wind velocity depends to an appreciable degree on the sea roughness. In using the graphs for the desired reductions of wind velocities for a given storm, it was necessary to assume a value for the sea roughness. The value selected was $\epsilon_{1}=0.3 \mathrm{~cm}$. Evaluations from the data of wind tides given later in this paper confirm this chosen value as an average.

It will be remembered that the curves of figure 5 are based on a city roughness of value $\epsilon_{2}=1 \mathrm{ft}$ $(30.5 \mathrm{~cm})$. Accordingly, the figures show that if the sea roughness be $\epsilon_{1}=0.3 \mathrm{~cm}$, the wind velocity observed at the lake surface at a height $25 \mathrm{ft}$ above the water will be about 1.12 times the city wind velocity

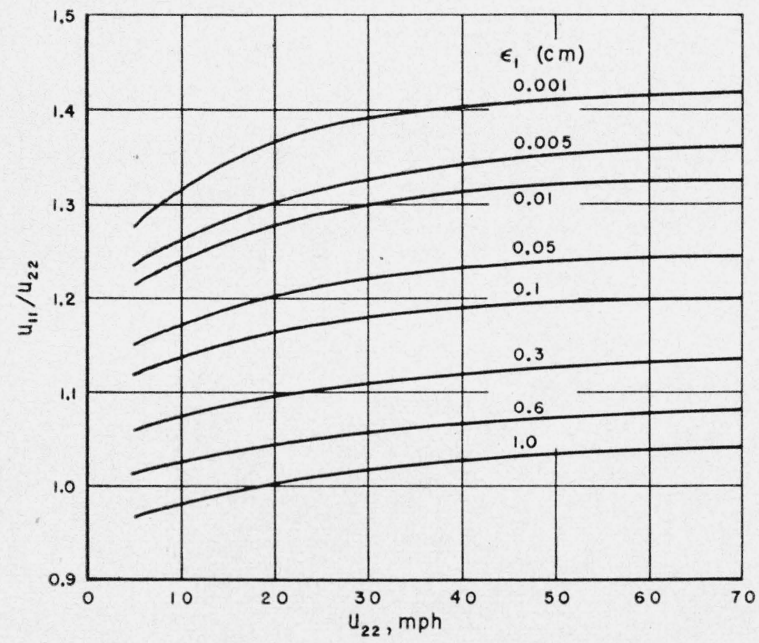

Figure 5. Relation between winds at a standard height of 25 feet over a lake, $u_{11}$, to winds at a standard height of 150 feet over a city, $u_{22}$, for various sea roughnesses. observed at a point $165(=150+15) \mathrm{ft}$ above the ground for the higher velocities of the city wind. It will be found, considering the data of figure 3 also, that if the city wind velocity be observed at a height $315 \mathrm{ft}$ above the ground, it gives the wind velocity over the lake. This is in agreement with the findings of Kadel [6] in an investigation of wind observations at Buffalo.

The roughness of the sea being much smaller than the roughness of a city, there is a change in the wind direction in passing from a city over a lake surface. The change is $\left(\phi_{s 2}-\phi_{s 1}\right)$, and the estimated values as deduced from the Rossby relations are shown in figure 6 . The magnitude of change depends on the wind velocity and the sea roughness. If the sea roughness be chosen as $\epsilon_{1}=0.3 \mathrm{~cm}$, the value of the average change is about $\left(\phi_{s 2}-\phi_{s 1}\right)=7^{\circ}$ for the higher wind velocities.

\subsection{Effective Lake Wind Velocity}

The third step is to determine the effective lake wind velocity, which is the velocity of the wind necessary to produce the observed wind tide under the condition that the wind blows with uniform intensity along the axis of the lake. When the actual winds at Toledo, Cleveland, Erie, and Buffalo during a storm are examined, it will be seen that these winds differ from each other in intensity and also in direction. The need for a formula to give the effective wind is readily seen.

The outlines of Lake Erie are shown in figure 7. The direction of a wind blowing from the south is

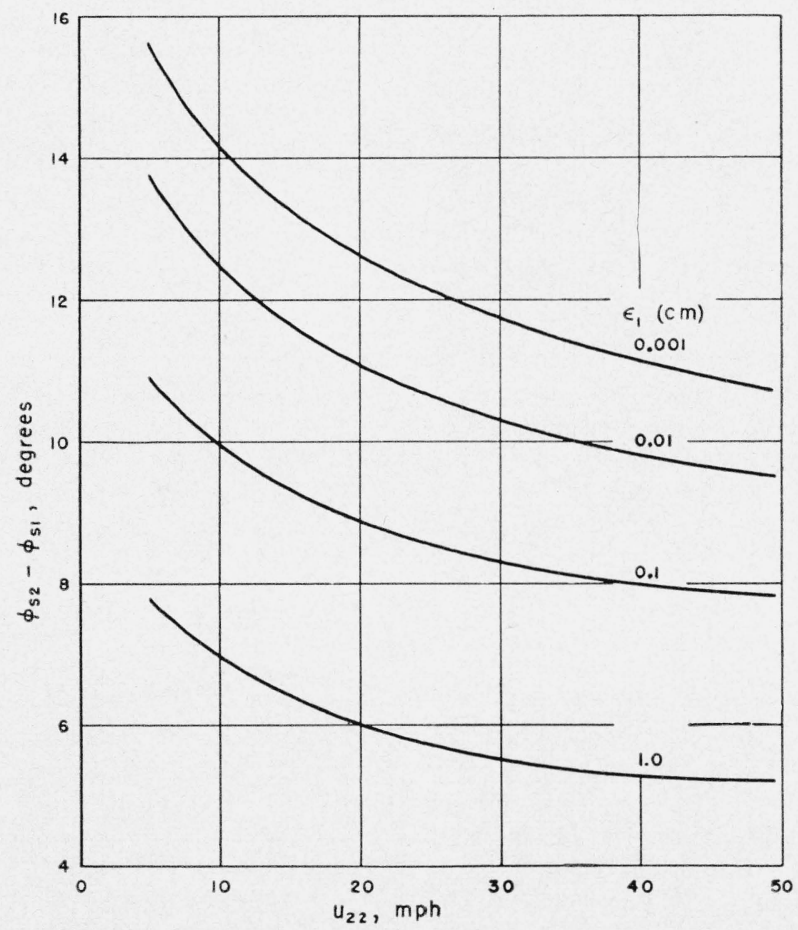

Figure 6. Difference in direction of winds over city and lake as function of wind velocity over the city for various values of the sea roughness. 


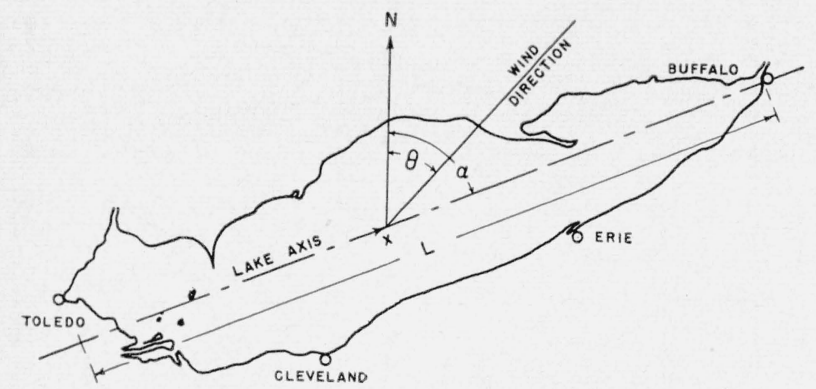

FIGURE 7. Sketch map of Lake Erie showing locations of cities considered and notation for directions.

chosen as the reference direction from which to measure wind directions. The lake axis is drawn so that it divides the area of the lake into two equal parts. Its direction is approximately $\alpha=68^{\circ}$. In the cross section through the point $x$ on the lake axis the velocity of the wind at an elevation of $25 \mathrm{ft}$ above the water surface is $u_{11}$, and its direction is $\theta$, an angle less than $180^{\circ}$. Denoting the effective lake wind by $V$ and the length of the lake axis by $L$,

$$
V^{2}=\frac{1}{L} \int_{0}^{L} u_{11}^{2} \cos (\theta-\alpha) d x
$$

This formula is applicable when $(\theta-\alpha)$ is small and the resulting wind velocity is large, for then the effect of the earth's rotation may be neglected and it may be imagined that the resultant movement of the water is in the direction of the lake axis. Putting $M=u_{11} / u_{22}$, where $u_{11} / u_{22}$ is determined by eq 8 , eq 9 becomes

$$
V^{2}=\frac{1}{L} \int_{0}^{L} M^{2} u_{22}^{2} \cos (\theta-\alpha) d x
$$

In this transformation no provision is made for the circumstance that the wind directions are not the same over the lake and over a city on the shore of the lake. Theoretically, in the above, denoting the difference $(\theta-\alpha)$ as $\beta$, the factor $\cos \beta$ must be replaced by $\cos (\beta+\gamma)$ where $\gamma$ is the difference $\left(\phi_{s 2}-\phi_{s 1}\right)$. Now $\cos (\beta+\gamma)=\cos \beta \cos \gamma-\sin \beta$ $\sin \gamma$, where $\gamma$ is a small quantity not exceeding $7^{\circ}$. Also the larger and significant values of wind tide are associated with winds for which the absolute values of $\beta$ are less than $\pi / 4$. Therefore it is readily seen that the resulting error is small when $\gamma$ is neglected.

When the exact variation of $u_{11}=M u_{22}$ as a function of $x$ is not known, the formulation must be based on discrete values of wind velocities. Let $V_{T}, V_{C}, V_{E}$, and $V_{B}$ be the wind velocities $u_{22}$ at Toledo, Cleveland, Erie, and Buffalo. The corresponding values of $M$ and $\theta$ are denoted by the same subscripts. Let the lake axis be divided into three segments of equal length. It may be supposed that the winds prevailing over the end segments are deducible from $V_{T}$ and $V_{B}$. The middle segment may be divided into two equal parts in which the winds are deducible

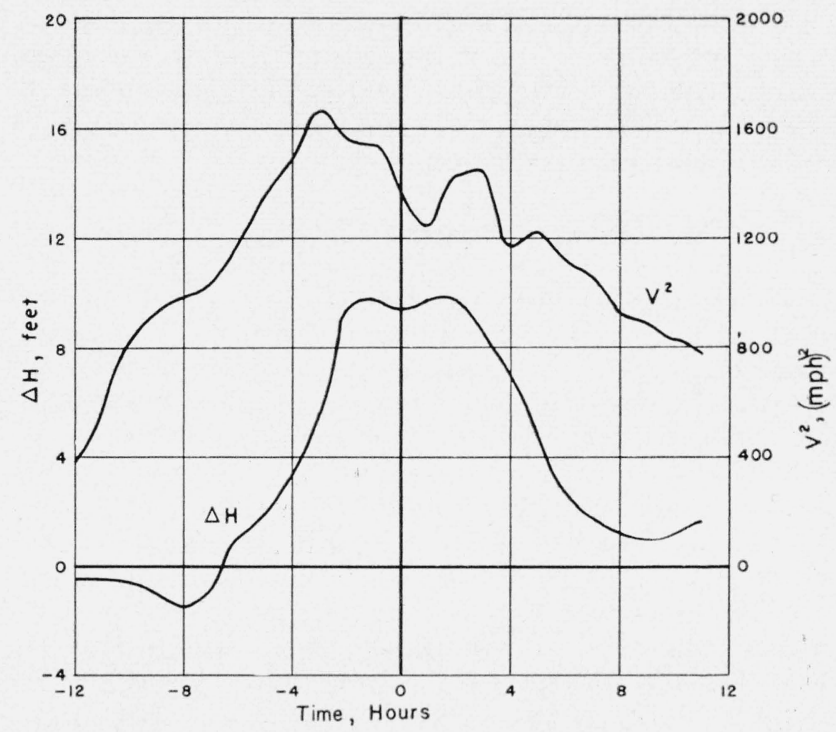

Figure 8. The reduced data for wind tides, $\Delta H$, and effective winds, $V$, for storm of December 31, 1911.

from $V_{C}$ and $V_{E}$. Thus instead of eq 10, we may write

$$
\begin{aligned}
V^{2}= & \frac{1}{3}\left[M_{T}^{2} V_{T}^{2} \cos \left(\theta_{T}-\alpha\right)+M_{B}^{2} V_{B}^{2} \cos \left(\theta_{B}-\alpha\right)+\right. \\
& \left.\frac{1}{2} M_{C}^{2} V_{C}^{2} \cos \left(\theta_{C}-\alpha\right)+\frac{1}{2} M_{E}^{2} V_{E}^{2} \cos \left(\theta_{E}-\alpha\right)\right] .
\end{aligned}
$$

Now for the higher wind velocities, in which we are interested, the variation of $M$ is not large as may be seen from the curves in figure 5. Therefore without significant loss of accuracy, we may write

$$
\begin{aligned}
V^{2}= & M^{2} V_{2}^{2}, \\
V_{2}^{2}= & \frac{1}{3}\left[V_{T}^{2} \cos \left(\theta_{T}-\alpha\right)+V_{B}^{2} \cos \left(\theta_{B}-\alpha\right)+\right. \\
& \left.\frac{1}{2} V_{C}^{2} \cos \left(\theta_{C}-\alpha\right)+\frac{1}{2} V_{E}^{2} \cos \left(\theta_{E}-\alpha\right)\right] .
\end{aligned}
$$

In this represent ttion $V_{2}$ is, in a sense, the effective city wind velocity for the southern coast of the lake over the entire length between the lake extremities. Values of $M$ as a function of $V_{2}$ are shown in table 1. The table is established on the basis of the curve in figure 5 associated with $\epsilon_{1}=0.3 \mathrm{~cm}$, after identifying $u_{22}$ as $V_{2}$ and $u_{11}$ as $V$.

TABLE 1. Dependence of the multiplying factor $M$ on the effective city wind velocity $V_{2}$

\begin{tabular}{|c|c||c|c|}
\hline$V_{2}^{2}$ & $M^{2}$ & $V_{2}^{2}$ & $M^{2}$ \\
\cline { 1 - 2 }$(m p h)^{2}$ & & & \\
\cline { 1 - 2 } 100 & 1.150 & & \\
\cline { 1 - 2 }$(m p h)^{2}$ & \\
200 & 1.300 & 1.254 \\
300 & 1.193 & 1,400 & 1.257 \\
400 & 1.205 & 1,500 & 1.260 \\
500 & 1.214 & 1,600 & 1.262 \\
600 & 1.223 & 1,700 & 1.264 \\
700 & 1.229 & 1,800 & 1.266 \\
800 & 1.234 & 2,900 & 1.268 \\
900 & 1.239 & 2,100 & 1.270 \\
1,000 & 1.243 & 2,200 & 1.272 \\
1,100 & 1.247 & 2,300 & 1.273 \\
1,200 & 1.251 & 2,400 & 1.274 \\
& & & \\
\hline
\end{tabular}


The method of velocity reduction explained above was applied to all the wind data of the storms under consideration. The final values of effective wind for the storm of December 31, 1911, are shown in figure 8 as a matter of illustration.

\section{Determination of Wind Tides}

If the nodal point of the displacements of the surface water in Lake Erie during a storm be known and also the level of the undisturbed water prior to the storm, the coefficient of wind stress may be obtained by considering the wind tide at either end of the lake. Practically, however, this method of evaluation has to be avoided as it is difficult to determine the nodal point and the level of the lake with exactness. It is more satisfactory to base the determination of the coefficient on the relative displacement of the water at the lake ends. This relative displacement is called the total wind tide, and is denoted by $\Delta H$. The displacements are observed at Toledo and at Buffalo. In the case of a westerly gale if $h_{B}$ is the wind tide at Buffalo and $h_{T}$ is the wind tide at Toledo, the total wind tide is $\Delta H=h_{B}-h_{T}$.

This method of total wind tides has another advantage in the case of Lake Erie which may be mentioned very briefly. The particular phases of the storm effects that are specifically useful in determining the coefficient of wind stress are the maxima of the wind tides. Now, because the lake ends differ in shape, the rates of rise and fall of the water levels are different for the two ends. For Buffalo, the top part of the curve of tides is generally pointed; for Toledo, flat. Moreover, the maxima at Buffalo tend to occur earlier than at Toledo. These differences become more pronounced when the maturing storm increases rapidly in intensity. By adopting the total wind tide as the datum to be treated, the effects of these peculiarities of the individual behaviors are somewhat reduced and thus the data become more reliable.

In some of the charts of the westerly gales received from the Lake Survey the displacements of water for the western end of the lake are shown for Gibraltar or Amherstburg. In these cases the wind tide indications shown had to be reduced to the Toledo values. For the reductions it was necessary first to establish the correlation between the displacements at these western localities. This was possible, since in some of the charts the simultaneous values of the displacements are shown. Also Blunt [2] gives values of the maximum displacements for these localities. Introducing all these in figure 9 and drawing a straight line through the plotted points, it is seen that on the average

$$
h_{T}=1.71 h_{A}
$$

where $h_{A}$ is the displacement of water either at Gibraltar or Amherstburg. This is the correlation to be applied.

A final matter to be considered relative to the observed values of the wind tides is the correction for the effect of barometric pressures. Ordinarily, when the gale is moving over the lake area the pressures at the two ends of the lake are unequal. When the gale

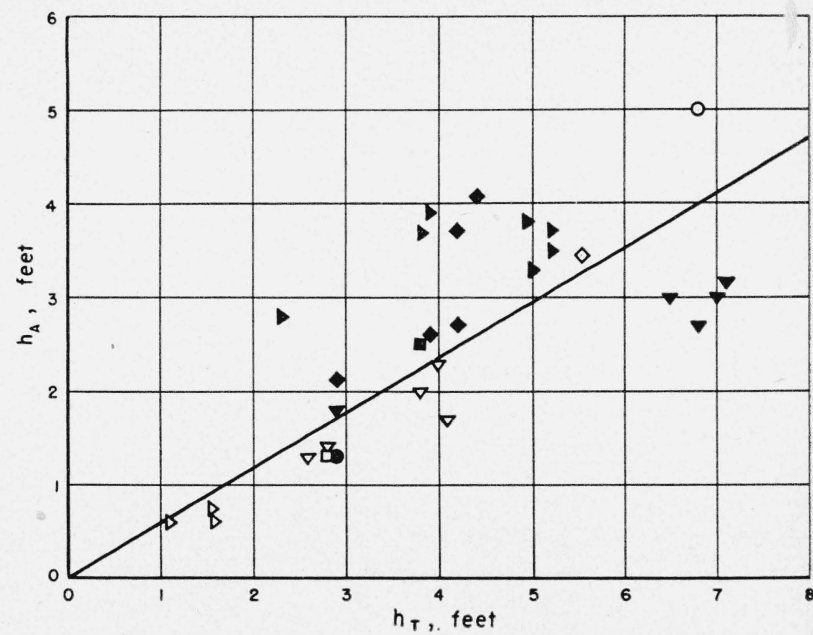

Figure 9. Correlation of wind tides at Toledo, $h_{T}$, with those at Amherstburg and Gibraltar, $h_{A}$.

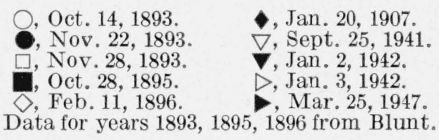

is a westerly, the greater pressure is at Buffalo. The difference of the atmospheric pressure at Toledo and Buffalo every hour of the storm period may be expressed as a head of water to be subtracted from the observed total wind tide.

\section{Data for Winds and Wind Tides of Lake Erie Storms}

The curves of wind intensity and total wind tide for the storm of December 31, 1911, shown in figure 8 are typical of all the storms considered in the presen. study. Taking the presentation in figure 8 as an example, it may be seen that the entire manifestation of the storm may be broken into three epochs; the epoch of maturing storm, the epoch of relative steadiness, and the epoch of recession. The hydrodynamical behavior of the water in the lake is expected to show marked differences during thesf epochs. In the initial epoch the wind must blow for some length of time before the response of the water to the action of the wind is completed. The reason for this condition is that any manifestation of wind tide must be associated with the flow of water from one end of the lake to the other. The action of the wind must establish a layer of drift current, the thickness of which must increase with time either under action of molecular viscosity, or turbulent viscosity, or both. As the water is being collected at the leeward end of the lake, a returning gravity current is created which likewise increases in intensity with time. The second epoch represents that steady condition in which the transport of water through the body of the drift current is counterbalanced by the transport of water in the returning gravity current that is maintained by the unchanging surface gradient of the lake waters. The third epoch is associated with decreasing wind intensity. With the 
trength of the wind decreasing, the stress of the wind cannot maintain the adverse gradient of the surface water with the result that a surge of water in vave motion with a period equal to the seiche period of the lake is produced. In some records these seiches with periods of $4 \mathrm{hr}$ are clearly seen during the time of the falling storm. The inertia effects are very pronounced in the extreme epochs: in the intermediate epoch they are considerably reduced.

For the determination of the relation between wind velocity and wind stress, only the manifestation of water level changes in the intermediate epoch will be considered. Referring once again to figure 8 , the reference time is the instant of maximum wind tide. In each case of the storms considered the reference time is evaluated by taking the average of the times of maximum deflection of water at the two ends of the lake. As the total wind tide of the intermediate epoch we have taken the average value of the wind tide over a duration of $4 \mathrm{hr}$ around the reference time. For the corresponding wind values we have taken the average value over a duration of $5 \mathrm{hr}$ immediately preceding the reference time.

The wind velocities and wind tides thus obtained from each record are entered in table 2 with the dates of the storms indicated. In some of the wind tide charts the storms showed two peaks with an extended flat region between them. The total tides of such regions are also included in the data of table 2 , and are identified with asterisks,

TABLE 2. Wind tides of Lake Erie during westerly gales

\begin{tabular}{|c|c|c|c|c|}
\hline No. & Date & $V$ & $T^{2}$ & $\Delta H$ \\
\hline $\begin{array}{l}1 \\
2 \\
3 \\
4 \\
5\end{array}$ & $\begin{array}{lr}\text { Nov. } & 21,1900 \\
\text { Oct. } & 20,1905 \\
\text { Oct. } & 20,1906 \\
\text { Jan. } & 20,1907 \\
\text { Dec. } & 7,1909\end{array}$ & $\begin{array}{l}m p h \\
50.5 \\
31.4 \\
38.3 \\
48.1 \\
40.1\end{array}$ & $\begin{array}{c}(m p h)^{2} \\
2549 \\
983 \\
1471 \\
2312 \\
1608\end{array}$ & \begin{tabular}{r}
\multicolumn{1}{c}{$f t$} \\
13.12 \\
6.68 \\
9.75 \\
12.04 \\
10.51
\end{tabular} \\
\hline $\begin{array}{c}6 \\
7 \\
8 \\
9^{*} \\
10\end{array}$ & $\begin{array}{lr}\text { Dec. } & 31,1911 \\
\text { Jan. } & 31,1914 \\
\text { Dec. } & 9,1917 \\
\text { Dec. } & 9,1917 \\
\text { Dec. } & 10,1907\end{array}$ & $\begin{array}{l}38.9 \\
34.7 \\
43.2 \\
33.1 \\
34.3\end{array}$ & $\begin{array}{l}1516 \\
1207 \\
1865 \\
1093 \\
1176\end{array}$ & $\begin{array}{r}9.53 \\
7.95 \\
10.17 \\
4.56 \\
7.62\end{array}$ \\
\hline $\begin{array}{l}11 \\
12 \\
13 \\
14^{*} \\
15^{*}\end{array}$ & $\begin{array}{lr}\text { Dec. } & 18,1921 \\
\text { Dec. } & 8,1927 \\
\text { Dec. } & 9,1927 \\
\text { Dec. } & 9,1927 \\
\text { Dec. } & 9,1927\end{array}$ & $\begin{array}{l}45.1 \\
47.4 \\
27.2 \\
26.1 \\
22.1\end{array}$ & $\begin{array}{r}2033 \\
2243 \\
742 \\
684 \\
487\end{array}$ & $\begin{array}{r}12.30 \\
13.24 \\
4.13 \\
3.44 \\
1.73\end{array}$ \\
\hline $\begin{array}{l}16 \\
17 \\
18 \\
19 \\
20\end{array}$ & $\begin{array}{lr}\text { April } & 1,1929 \\
\text { Jan. } & 22,1939 \\
\text { Sept. } & 25,1941 \\
\text { Jan. } & 2,1942 \\
\text { Jan. } & 3,1942\end{array}$ & $\begin{array}{l}51.3 \\
38.8 \\
35.7 \\
40.4 \\
19.5\end{array}$ & $\begin{array}{r}2634 \\
1508 \\
1277 \\
1632 \\
379\end{array}$ & $\begin{array}{r}13.31 \\
9.40 \\
9.06 \\
12.53 \\
2.38\end{array}$ \\
\hline $\begin{array}{l}\therefore 1 \\
22\end{array}$ & $\begin{array}{l}\text { Nov. } 22,1946 \\
\text { Mar. }{ }^{¿ 5}, 1947\end{array}$ & $\begin{array}{l}34.2 \\
35.7\end{array}$ & $\begin{array}{l}1171 \\
1276\end{array}$ & $\begin{array}{l}8.36 \\
8.34\end{array}$ \\
\hline
\end{tabular}

The square of the wind velocities, $V^{2}$, near the lake surface and the corresponding wind tides, $\Delta H$, taken from table 2 are plotted in figure 10 . Comparing the position of the plotted points with respect to the full line drawn, it is seen that the data corresponding to high wind velocities show small deviations from the curve, whereas those corresponding to low wind velocities show proportionately larger deviations, and all towards lower values of $\Delta H$. One inference is that the wind stress for low

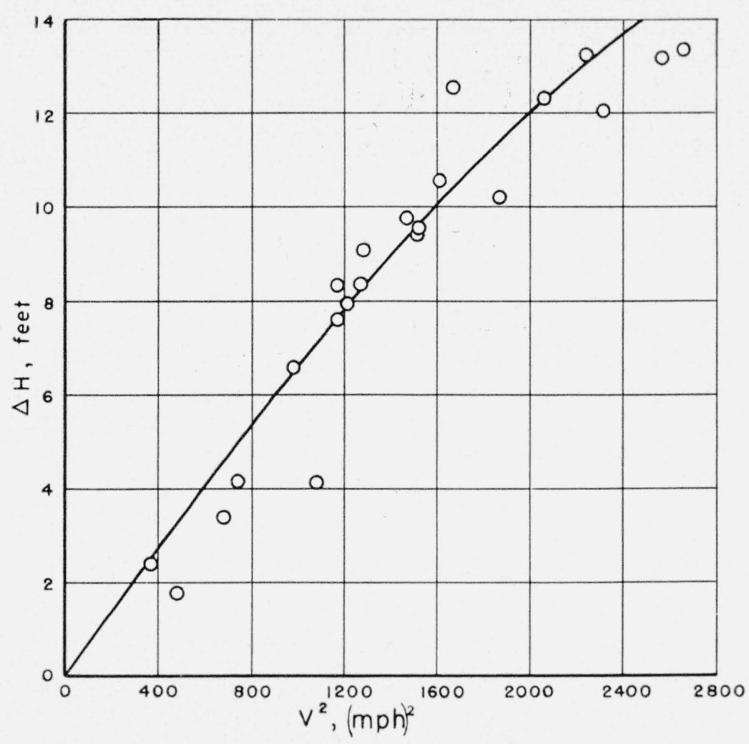

Figure 10. Wind tides in Lake Erie.

Data for plotted points taken from table 2 .

wind velocity is relatively smaller. Unfortunately, the observations for the lower wind velocities are not sufficiently numerous to establish this point beyond doubt.

\section{Integration of the Wind Tide Equation for Lake Erie}

First the wind tide differential equation for a lake of arbitrary shape will be derived. Let positive $x$ be drawn along the direction of the wind, this direction coinciding with the axis of the lake. At the point $x$ the wind tide is $h$, it being the elevation of the raised water surface with respect to the level of the undisturbed water. See figure 11. Corresponding to $h$ at $x$ the surface width of the water is $B$, the cross-sectional area is $A$, and the mean depth is $\bar{H}$. The cross section is normal to the axis of the lake. The velocity of the wind is $V$, and the corresponding wind stress is $\tau_{s}$. At the bottom the stress induced by the gravity current is $\tau_{0}$. The density of water is $\rho$ and that of air is $\rho_{a}$. Two sections $\Delta x$ apart, one at $x$ and the other at $x+\Delta x$, are taken. If the total pressure force on the section at $x$ be denoted by $P$, the pressure force on the section at $x+\Delta x$ will be $P+A \rho g(d h / d x) \Delta x$. Hence, the difference of the two pressure forces is $A \rho g(d h / d x) \Delta x$. The inertial action of flow in the drift current above and in the gravity current below being ignored, the

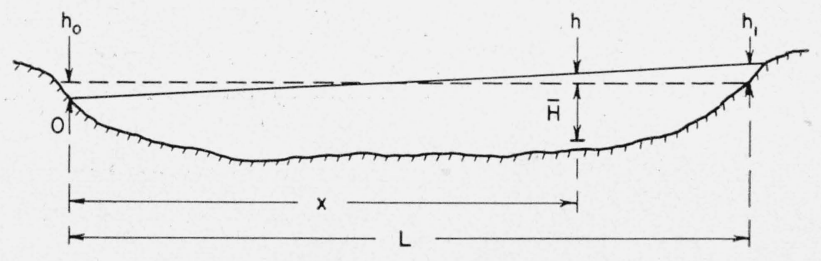

Figure 11. Notation diagram for wind tides.

$\bar{H}$ is the mean depth in the cross section of the lake at $x$ 
only remaining counterbalancing forces are the frictional forces amount to $B\left(\tau_{s}+\tau_{0}\right) \Delta x$. Thus, equating the forces and dividing by $\Delta x, A \rho g(d h / d x)=B$ $\left(\tau_{s}+\tau_{0}\right)$, and since $A=B(\bar{H}+\dot{h})$, then

$$
\frac{d h}{d x}=\frac{\tau_{s}+\tau_{0}}{\rho g(\bar{H}+h)},
$$

which is the wind tide equation for a lake of arbitrary shape. As the volume of water in the lake is not changed, the condition of continuity reduces to

$$
\int_{0}^{L} B h d x=0
$$

where $\mathrm{L}$ is the length of the lake axis.

Equations 13 and 14 may be changed into dimensionless forms. The average section depth may be expressed in terms of the average lake depth $H_{0}$,

$$
H_{0}=\frac{1}{\bar{B} L} \int_{0}^{L} B \bar{H} d x
$$

The section surface width may be expressed in terms of the average lake width, $\bar{B}$,

$$
\bar{B}=\frac{1}{L} \int^{L} B d x .
$$

The distances along the axis may be expressed in terms of the lake length, $L$.

\section{Putting}

$$
\begin{gathered}
\sigma=\frac{\tau_{s}+\tau_{0}}{\rho g H_{0}} \cdot \frac{L}{H_{0}}, \\
\eta=\frac{h}{H_{0}},
\end{gathered}
$$

and

$$
\zeta=\frac{x}{L}
$$

eq. 13 and 14 reduce to

and

$$
\frac{d \eta}{d \zeta}=\frac{H_{0} / \bar{H}}{\left(1+\eta H_{0} / \bar{H}\right)} \sigma,
$$

$$
\int_{0}^{1} \frac{B}{\bar{B}} \eta d \zeta=0
$$

It is important to remark that $\sigma$ is the parameter of stress, $\eta$, the parameter of wind tide, $\zeta$, the parameter of distance. In a lake of arbitrary shape $H_{0} / \bar{H}$ and $B / \bar{B}$ are functions of $\zeta$.

As ordinarily $\eta$ is a small quantity, eq 20 may be written in the form

$$
\frac{d \eta}{d \zeta}=\sigma \frac{H_{0}}{\bar{H}}\left(1-\frac{H_{0}}{\bar{H}} \eta\right)
$$

The solution of the equation may be expressed in the form

$$
\eta=\sigma F_{1}(\zeta)-\sigma^{2} F_{2}(\zeta)
$$

where

$$
\begin{gathered}
F_{1}(\zeta)=C_{1}+\int_{0}^{\zeta} \frac{H_{0}}{\bar{H}} d \zeta, \\
F_{2}(\zeta)=C_{2}+\int_{0}^{\zeta}\left(\frac{H_{0}}{\bar{H}}\right)^{2} F_{1}(\zeta) d \zeta,
\end{gathered}
$$

the quantities $C_{1}$ and $C_{2}$ being the constants of integration. Now, from eq 21

$$
\int_{0}^{1} \frac{B}{\bar{B}} F_{1}(\zeta) d \zeta=0
$$

and

$$
\int_{0}^{1} \frac{B}{\bar{B}} F_{2}(\zeta) d \zeta=0
$$

and these serve to evaluate the constants $C_{1}$ and $C_{2}$.

To carry out the determinations of the functions $F_{1}$ and $F_{2}$, it is necessary to obtain the shape quantities $\bar{H} / H_{0}$ and $B / \bar{B}$ for Lake Erie. These quantities as determined from the Lake Survey Office map of Lake Erie are shown in figures 12 and 13 . Using the data from the figures, and following the method of computation shown above, the functions $F_{1}$ and $F_{2}$ are determined. These are plotted in figure 14. For the subsequent analysis the end values

$$
\begin{aligned}
& F_{1}(0)=-0.641, \quad F_{2}(0)=0.323, \\
& F_{1}(1)=0.512, \quad F_{2}(1)=0.118,
\end{aligned}
$$

are important.

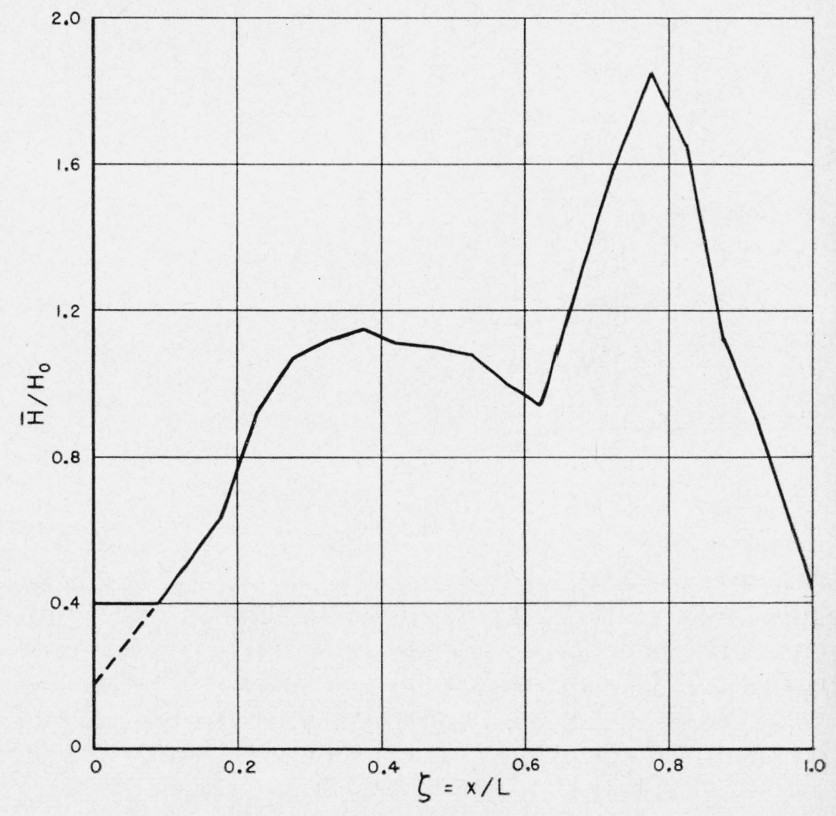

Figure 12. Mean depths of Lake Erie as function of distance from Toledo. 
Expressing the shear at the lake bottom as a fraction of the wind stress,

$$
\tau_{0}=n \tau_{s},
$$

the relation in eq 30 may be written as

$$
\tau_{s}=\frac{1}{1+n}\left[0.867 \frac{\Delta H}{H_{0}}-0.134\left(\frac{\Delta H}{H_{0}}\right)^{2}\right] \frac{H_{0}}{L} \rho g H_{0} .
$$

Introducing the definition of the coefficient of wind stress,

$$
\tau_{s}=\chi \rho_{a} V^{2},
$$

where $\rho_{a}$ is the density of air, and $V$ the velocity of the wind, we have from eq 32

$$
\chi=\frac{0.867}{1+n}\left[1-0.16 \frac{\Delta H}{H_{0}}\right] \frac{\Delta H}{H_{0}} \frac{\rho}{\rho_{a}} \frac{g H_{0}}{V^{2}},
$$

which is the proper formula to evaluate the coefficient of wind stress from the total wind tide observed at Lake Erie. In the application of the formula the depth of water $H_{0}$ is taken as $58 \mathrm{ft}$., the ratio of the density of water to the density of air, $\rho / \rho_{a}$, as 1,250 . The wind velocities $V$ are to be expressed in feet per second and the wind tides $\Delta H$ in feet. It may be supposed that the frictional stress of the lake bottom is about one-tenth of the wind stress. Accordingly, $n$ is 0.10 .

Applying the above formula to the set of wind intensities and corresponding wind tides appearing in table 1, a set of values of the wind stress coefficient are obtained which are entered in table 3 . The same

TABLE 3. Coefficient of wind stress deduced from Lake Erie gales

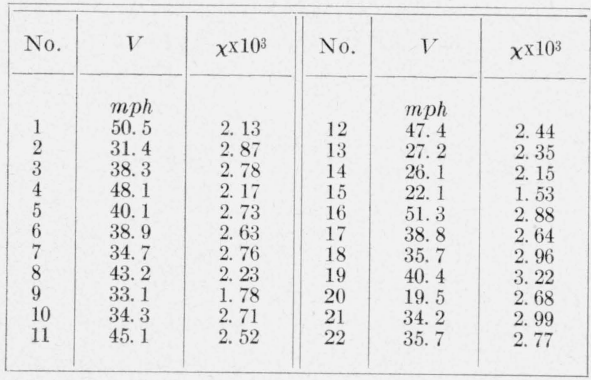

data are plotted in figure 16 as full circles. Plotted in the same figure as open circles are the wind stress coefficients which Neumann obtained in an examination of the Pelman observations for the Gulf of Bothnia [7]. Neumann's original values were reduced to correspond to winds $25 \mathrm{ft}$ above the surface of the water.

An examination of figure 16 reveals that in the region of the higher wind velocities the coefficient of wind stress is practically independent of the velocity of the wind. Furthermore, the coefficient of wind stress for the two bodies of water are of like value. The average value of the individual determinations is 0.00254 for Lake Erie, and 0.00236 for the Gulf of

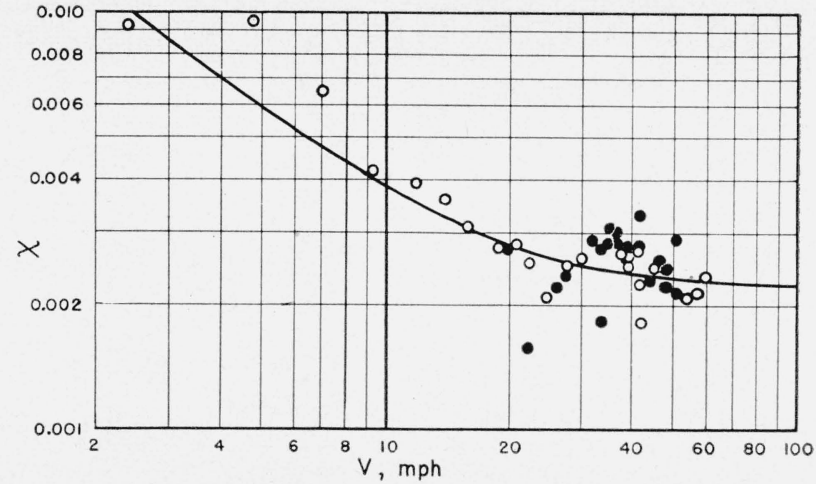

Figure 16. Comparison of coefficients of wind stress in Lake Erie and the Gulf of Bothnia.

- Lake Erie. O, Gulf of Bothnia.

Bothnia. Now, the data from the Gulf of Bothnia for low wind velocities indicate that for this region the coefficient of wind stress is not constant but decreases with increasing wind. At the moment no similar data are at our disposal for Lake Erie and efforts are being made to remedy this gap in our investigation.

\section{Evaluation of Sea Roughness}

We shall adopt for the determination of sea roughness the procedure used by Neumann. Writing eq 33 in the form $\left(V / V_{*}\right)^{2}=\chi^{-1}$, substituting in

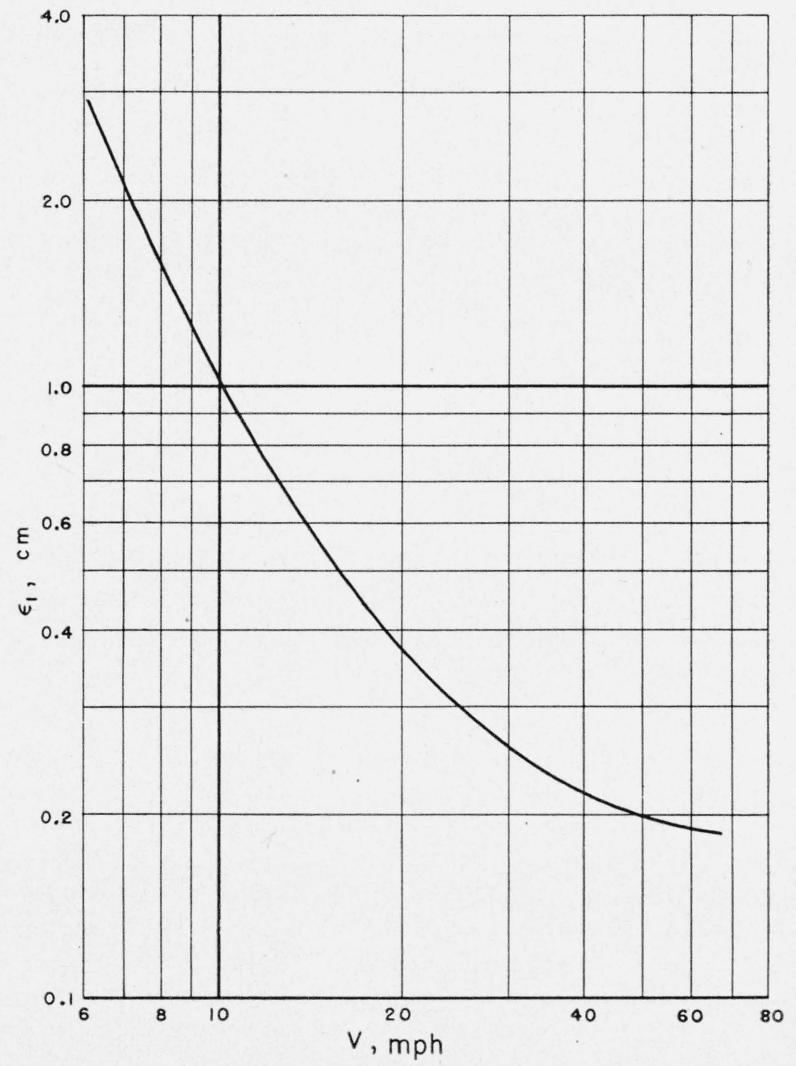

Figure 17. Variation of sea roughness, $\boldsymbol{\epsilon}_{1}$, with wind velocity, $V$. 
eq 1 , and changing $\epsilon$ to $\epsilon_{1}$, there is obtained

$$
\frac{1}{\sqrt{\chi}}=5.75 \log \frac{z_{11}}{\epsilon_{1}}
$$

which relates the sea roughness $\epsilon_{1}$ to the elevation $z_{11}$ for which the wind is determined and the coefficient of wind stress $\chi$. In the present case, since $\chi$ is determined from wind velocities prevailing at a height of $25 \mathrm{ft}, z_{11}=25 \mathrm{ft}$, or $762 \mathrm{~cm}$. As mentioned above, the average value of the coefficient of wind stress from the Lake Erie data is 0.00254. This yields for the sea roughness the value $\epsilon_{1}=0.27 \mathrm{~cm}$. As will be remembered, in the computations required to reduce the city wind velocities to the lake velocities it was necessary to assume the value of the sea roughness beforehand. The assumed value was $\epsilon_{1}=0.3 \mathrm{~cm}$, and this selection is now seen to be satisfactory.

The full line drawn through the data points of figure 16 may now be used to investigate the variation of sea roughness with wind velocity. Using values from the curve and the formula above, eq 35 , the results of the computations are given in figure 17 in the form of a curve. With increasing wind velocities the magnitude of the roughness decreases. When the higher wind velocities are attained, the roughness approaches a constant value, practically.

We refrain at the present moment from discussing the theoretical significance of the facts that both the coefficient of wind stress and the sea roughness decrease with increasing wind velocities.

\section{References}

[1] John R. Freeman, Regulation of the Great Lakes, Report to Board of Trustees of the Sanitary District of Chicago, p. 201. (1925).

[2] Wm. T. Blunt, Effects of gales on Lake Erie, Report of U. S. Deep Waterways Commission, p. 155 (1897).

[3] L. Prandtl, Meteorologisehe Anwendung der Strömungslehre, Beitrage zur Physik der freien Atmosphäre, 19, p. 188. (1932).

[4] M. Siotani and G. Yamamato, Atmospheric turbulence over the large city. J. Meteorl. Soc: Japan, 2d Series, 2\%, 111 . (1949).

[5] C. G. Rossby and R. B. Montgomery, The layer of frictional influence in wind and ocean currents; Papers in Physical Oceanography and Meteorology, III, No. 3, Cambridge, Mass.

[6] Benjamin C. Kadel, Anemometer records on a Buffalo office building compared with those secured near the surface of Lake Erie. Monthly Weather Rev. (April 1917).

[7] Gerhard Neumann, Űber den Tangentialdruck des Windes und die Rauhigkeit der Meeresüberfläche, Zeit. für Meteor. Year 2, p. 193 (1948).

Washington, November 3, 1952. 